\title{
LAS PINTURAS DE LA HERMANDAD DE SAN PEDRO AD VINCULA
}

\author{
José Fernández López
}

La Ilustre y Venerable Hennandad de Sacerdotes Beneficiados de San Pedro ad Víncula, fue fundada en Sevilla en el último tercio del siglo XVI, atribuyéndose sus inicios a la labor del Racionero de la Santa Iglesia Metropolitana, licenciado Andrés Segura, quien fundó en 1571 el convento de religiosas agustinas de Nuestra Señora de la Paz, primera sede de la Corporación y de donde se conocen sus primeras noticias de carácter histórico. Entre estas noticias cabe destacar la reorganización de la Hermandad llevada a cabo en 1582 por el entonces Rector Fray Gaspar de Torres, de la Orden de la Merced, obispo de Medauro, con otros eclesiásticos (1). De este año data también la primera Regla, aprobada en el cabildo celebrado el 25 de septiembre. Esta Regla fue reformada en dos ocasiones en el siglo XVII, en 1609 y 1686, y más tarde en 1733 y 1873, antes del presente siglo.

El dia 15 de junio de 1583, la Hermandad se trasladó a la Parroquia de San Pedro, donde estableció su sede, ocupando la capilla que perteneció al Jurado, Alonso de Vega. El 27 de noviembre de 1608 se le otorgó, mediante escritura pública ante el escribano Pedro Almonacid, por el presbítero licenciado Juan Gómez Vallejo, Administrador de Fábrica de la parroquia, con licencia del Provisor del arzobispado Jerónimo de Leyba, lugar para edificar capilla propia y otras dependencias. Posteriormente Juan Gómez Vallejo cedió, por escritura efectuada el 15 de octubre de 1610, ante el escribano Gaspar de León, dos habitaciones reservadas a la Fábrica de la parroquia de

(1) Hermandad de los senores sacerdotes seculares de S. Pedro ad Vínala. Libro 1.? de acuerdos, 1582-1699, pág. 3. Este libros no se conserva actualmente. La Corporación sólo poseo un Indice manuscrito del mismo, rodactado por el presbitero mayordomo de la Hermandad D. José M.: Tobla y Femández, que tue la base documental para la redacóón de la resena histórica que figura en la Regla reformada de la ilustro Hermendad..., de San Pedro ad Vinada, Sevilla, 1873. 
San Pedro. Por lo tanto, la Hermandad de San Pedro ad Víncula emprendió en breve plazo de tiempo la ejecución de capilla propia, enterramiento, sala capitular y dependencias de servicio, por las que habría de pagar a la parroquia dos mil doscientos cincuenta maravedíes de renta anual (2).

La construcción de la capilla y demás dependencias debió ser rápida, pues se tiene constancia de la celebración en ellas de solemnidades y funciones hacia 1613. Un año antes, el 21 de marzo de 1612, el clérigo pintor Juan de Roelas había solicitado ser hermano numerario de la Corporación, entregando, a cambio de la cuota de ingreso y de un libro de la Regla de 1609, el lienzo de La liberación de San Pedro por el ángel, sobre cuya realización ya andaba en tratos con la Hermandad, lo que induce a pensar que en esa fecha las obras estuviesen muy avanzadas, pues los hermanos de San Pedro ad Víncula pensaban ya en la decoración de su capilla (3).

Fue a lo largo del siglo XVII cuando la Hermandad conoció los momentos' de mayor auge, participando corporativamente en los acońtecimientos religiosos más significativos de la ciudad. Caracterizó a sus miembros la honda devoción procesada al Misterio de la Inmaculada Concepción de María, lo que les hizo partícipes del furor inmaculadista que se desató en Sevilla en el segundo decenio del siglo. Tomó parte la Hermandad en todos los actos de desagravio, de solemne juramento litúrgico, festivos y literarios; anteriores y posteriores a la divulgación del Breve de Pablo $\mathrm{V}$ favorable a la Opinión pía sobre el Misterio. De gran repercusión en la ciudad fueron los solemnes cultos que la Hermandad dedicó a la Inmaculada, en el octavario iniciado el 19 de junio de 1616, y en la justa literaria organizada posteriormente, cuya duración se extendió hasta el 20 de julio del mismo año. Estas fiestas religiosas tuvieron su inicio doce o trece días antes del octavario con una piadosa procesión que hizo estación en diversos templos sevillanos. Todas estas celebraciones, recogidas por el licenciado Francisco de Luque Fajardo en su Relación de las fiestas que la Cofradía de Sacerdotes de San Pedro ad Víncula celebró en la Parroquial Yglesia de Sevilla a la Puríssima Concepción de la Virgen

(2) Regla reformada de la ilustre Hermandad..., de San Pedro ad Vincula, Sevilla, 1873, pág. IV y V.

(3) Hermandad de los senores sacerdotes seculares de S. Pedro ad Vincula. Libro 1.0 de acuerdos, 1582-1699, pág. 42; Mayer, A. L., Die Sevillaner Malerschülé, Leipzig, 1911, pág. 103. Documento VII, pag. 217. 
María Nuestra Señora, publicada en Sevilla, en 1616, tuvieron como fin conmemorar el voto inmaculadista de los miembros de la Hermandad (4).

La capilla de la Hermandad de San Pedro ad Víncula es la última de las situadas en la nave de la Epístola de la parroquia de San Pedro. Su planta es la de un paralelepípedo irregular, al ser la pared de la cabecera más larga que la de la reja de entrada. La cubierta de este espacio arquitectónico es plana y sobre ella se halla una habitación para las dependencias de là Hermandad. El interior de la capilla está decorado con once pinturas dispuestas en las paredes de forma no totalmente simétrica, aunque sí con una cierta ordenación, que no es en absoluto iconográfica. Nueve de estas pinturas, aunque de tamaño y técnica irregulares, componen un programa unitario en cuanto a su temática y estilo artístico, a pesar de poseer algunas características diferenciadoras. De las otras dos pinturas, La liberación de San Pedro por el ángel, de Roelas, sí guarda, evidentemente, relación con el conjunto anterior, a pesar de su calidad artística muy superior, mientras que el retrato de San Millán de la Cogolla, de significación eclesiológica, muestra al virtuoso santo español, que recibió las órdenes sagradas y fue párroco. Vamos a analizar este conjunto de pinturas siguiendo en ello el orden aproximado o provisional de su ejecución.

En 1612, Juan de Roelas realizó La liberación de San Pedro por el ángel, ingresando por ello, entre el reducido número de clérigos hispalenses pertenecientes a la Hermandad (5). Esta obra resulta vital para entender la evolución artística de Roelas y el impulso decisivo que este pintor representa en la escuela sevillana del primer tercio del siglo XVII. Roelas utilizó en ella por primera vez recursos lumínicos de carácter tenebrista al hacer incidir potentemente la luz emanada del farol sostenido por el ángel, frente a la penumbra reinante en la prisión en la que se halla el Santo. Esta iluminación hace resaltar también la corporeidad de las figuras, así como su expresión gestual, en la que destaca la serenidad del ángel y el rostro sorprendido y receloso de San Pedro (6).

(4) A este aspecto resulta de interés la lectura del folleto anónimo editado por la Hermandad: Historia concepcionista osea Reseña de las demostraciones de veneración y culto..., de San Podro adVincula de la ciudad de Sevilla. Sevilla, 1905.

(5) Regla y estatutos de la Hermandad de Senores sacerdotes de nuestro padre el Sentor $S$. Pedro Advíncula..., Sevilla, 1733, pág. 8. El capítulo segundo de esta Regla limita el número de hermanos, activos, a cien.

(6) Lienzo, 305×207 cms. 
Las nueve pinturas restantes, cuya temática está relacionada directamente con la vida de San Pedro, son de calidad artística considerablemente menor al compararlo con el lienzo de Juan de Roelas y de tamaño inferior. Todo ello ha provocado que su estudio pasara casi desapercibido.-Gestoso, en 1889, fechó estas pinturas en el siglo XVII, mencionando su mal estado de conservación; aunque tal vez se refiera a los modestos frescos decorativos que posee la capilla, mal restaurados a mediados de este siglo (7). María Teresa Dabrio apuntó, en 1975, la posibilidad de que estas pinturas fueron las tablas del antiguo retablo mayor, realizadas, hacia 1541, por Alejo Fernández y Cristóbal Cárdenas, debido a la influencia flamenca patente en alguna de ellas (8). Sin embargo, el estilo de estas obras nos permiten fecharlas muy posteriormente, en un lapso de tiempo que comprende los años finales del siglo XVII y los iniciales del siglo XVIII. Su influencia flamenca se explicaría tanto por la presencia en Sevilla en la segunda mitad del siglo.XVII de pintores de esa procedencia, como, sobre todo, por el uso de estampas y grabados del mismo origen, base para la realización de composiciones pictóricas, fundamentalmente, al igual que el caso que nos ocupa, cuando estas son de taller. El estilo de estas pinturas está muy cercano al del taller del pintor Matías de Arteaga, muy activo en la Sevilla de aquella época.

Cinco de estas composiciones tienen parecida, aunque no similar, forma y tamaño. Aparecen enmarcadas en una moldura dorada que en su parte superior se divide en dos medios puntos a través de una especie de ménsula. La pintura situada a la izquierda tras la reja de entrada a la capilla es la de menor tamaño entre las situadas a mayor altura. Las dos obras de mayor dimensión física de esta serie, situadas bajo los dos vanos de la pared derecha de la capilla, están enmarcadas en ricas molduras doradas dieciochescas (9). Técnicamente también existen diferencias de ejecución en este grupo de pinturas. Las siete situadas a mayor altura están realizadas al fresco, con el óleo como vehículo del color. Las dos ubicadas bajo los vanos están realizadas al óleo sobre tabla.

Observemos el contenido de cada una de estas pinturas iniciando este recorrido, tras el ingreso en la capilla, por el lado izquierdo. La primera, la de

(7) Gestoso, J., Sevilla monumental y antistica, Sevilla, 1889-1892, ed. 1984, t. I, pág. 238.

(8) Dabrio, M.' T., Estudio historico antistico de la Parroquia de San Pedro de Sevilla, Sevilla, 1975, pág. 96.

(9) Seis de estas pinturas miden $92 \times 86 \mathrm{cms}$., salvo la situada a la izquierda, tras el ingreso en la capilla, cuya anchura es considerablemente menor, pero que hasta el momento ha sido inaccesible para su medida. 
menor tamaño, representa las Lamentaciones o Arrepentimiento de San Pedro, tema típicamente contrarreformista que revaloriza la Confesión y la Penitencia ante la crítica a estos sacramentos por la Reforma protestante. Tras ella aparece la escena de los Hechos de los Apóstoles (3, 12-26), San Pedro predicando en el templo, ante el pueblo y los sacerdotes. Consecuencia directa de la pintura anterior es la representación siguiente, San Pedro y San Juan ante el Senedrín (Hechos de los Apóstoles 4, 5-30), ante el cual fueron conducidos ambos apóstoles después de la predicación en el templo el día precedente.

Los temas situados a los laterales del cuadro del altar de Roelas, tienen un carácter iconográfico devocional y a la vez doctrinal. El situado a la izquierda, San Pedro ante Cristo flagelado, es una representación de tipo devoto, tradicional en la religiosidad española, que muestra la unión de la imagen del arrepentimiento de San Pedro, con la de Cristo, Varón de Dolores. A la derecha se sitúa las Negaciones de San Pedro (Evangelios de San Marcos 14, 66-72; San Mateo 26, 69-75; San Lucas 22, 54-62; San Juan 18, 15-18, 25-27). Esta pintura, a pesar de sus errores de composición y lo desacertado de la disposición de los personajes, revela en conjunto su débito de esquemas pictóricos flamencos, así como la influencia ejercida sobre su autor por los modelos físicos de Valdés Leal y Murillo. Estos condicionantes estéticos apuntados en último lugar, presentes en el trabajo de Matías de Arteaga, nos hacen pensar en la presencia del taller de este pintor en la ejecución de estas obras.

A continuación, en la pared oblicua, figura la representación de San Pedro curando a un tullido (Hechos de los Apóstoles 3, 11), imagen en la que se ha continuado la disposición iconográfica habitual de este tema en la pintura sevillana del siglo XVII, siguiendo, como indicó Martín Soria, las fuentes grabadas por Felipe de Galle y Martín de Vos, aunque de forma libre (10). En las tablas situadas bajo los vanos se muestran dos escenas extremas de la vida apostólica de San Pedro. De una parte la Vocación de San Pedro y San Andrés (Evangelio de San Marcos 1, 16-18), momento inicial de la vida de Pedro como discípulo de Cristo. Por otro lado el Martirio o Crucifixión de San Pedro, visión tomada por los Evangelios apócrifos, aceptada por la ortodoxia católica como exaltación

(10) Soria, M., "Zurbaran's Altar of St. Peter" en The Art. Bulletin, 1951, págs. 165-173; Guinard, P., Zurbarán et les peintres espagnols de la vie monastique, Parla, 1960, pág, 140. 
gloriosa de las cualidades del primero de los papas que culminaron en el martirio. La última de las pinturas realizadas al fresco se encuentra en un estado deplorable, por lo que su identificación resulta difícil, pudiendo tratarse de La liberación de San Pedro por el ángel (Hechos de los Apóstoles 12, 6-10), aunque con todo tipo de reservas.

Cierra la decoración pictórica de la capilla de la Hermandad de San Pedro ad Víncula el Retrato de San Millán de la Cogolla, de cuerpo entero, ante un amplio paisaje en el que se muestran sus predicaciones. El cuadro contiene en la parte inferior derecha la siguiente inscripción: "Retrato de San Millán de Cogolla Patrón de Es/paña con Santiago fue/clérigo y después Mon/ge del Orden de San Benito" (11). El lienzo fue regalado a la Hermandad por un devoto, pero no permaneció siempre en el interior de la capilla. Este retrato es una obra discreta de mediano interés, mal conservada, de autor anónimo y fechable hacia 1700. De hecho ya figuraba en un Inventario de la Hermandad de inicios del siglo XVIII, así como en el de 1879 (12).

Un somero análisis iconológico de las pinturas de la capilla de la Hermandad de San Pedro ad Víncula revela un contenido fundamentalmente eclesiológico. Los temas de la vida de San Pedro fueron abundantes dentro de la nómina de pinturas sevillanas de los siglos XVII y XVIII. Sin embargo, sólo se conserva otro conjunto relacionado iconográficamente con la vida del Apóstol, el retablo que pintara Francisco Zurbarán para la Catedral de Sevilla, en la capilla del marqués de Malagón, hacia 1630, fecha ampliamente discutida por la historiografía artística sobre este pintor. Estos conjuntos dedicados a la vida de San Pedro responden a una idea contrarreformista de lucha por la defensa del Orden Sacro, atacado por la Reforma protestante, en especial en su aspecto jerárquico y por ello en la figura del Papa. El primero de los papas fue San Pedro, de quienes luteranos y calvinistas dudaron que fuera "la piedra" sobre la que Cristo edificara su Iglesia. Frente a estos ataques la Iglesia, y su espíritu nuevo emanado del Concilio de Trento, luchó con

(11) Lienzo, $165 \times 120 \mathrm{cms}$.

(12) Dabrio, M.' T., ob. cit., pág. 97, nota n.? 8; "Inventario de los efectos pertenecientes a la Venerable Cofradla de Sefiores Sacerdotes de N. Padre Sr. San Pedro ad Vincula que esta ciudad de Sevilla formado en primero de Enero de 1880 para entrega que hace el Sr. D. José M.e Tobia y Fernández, mayordomo comunal en el afio anterior al Sr. D. José de la Fuente y Zabalegui nombrado para este anto en el cabildo general de elecciones colebrado el 29 de Diciembre de 1879". En esta memoria e inventario se cita el cuadro de Roelas, las tablas de la capilla, ef lienzo de Sen Millén de la Cogollay dos cuadros más que representaban un Attar de ánimas y las Indulgencias. 
todas las armas doctrinales y dogmáticas a su alcance (13). En los decretos trentinos dedicados a la "Reforma del Orden", se dejaba bien patente y fuera de toda discusión que los intentos de reforma se realizaban desde la cúpula jerárquica de la Iglesia. Por otro lado se especificaba que el ataque al papado lo era también a todo el estamento eclesiástico y a toda la ordenación que regía el orbe católico (14). Por lo tanto, la iconografía de San Pedro y los programas artísticos sobre su vida y sus hechos, guardan un íntimo significado de defensa de la dignidad eclesiástica y de su orden. La Hermandad de San Pedro ad Víncula, al igual que otras hermandades sacerdotales sevillanas, no asistenciales, como la de la Cátedra de San Pedro, de la iglesia de Santa María la Blanca, o la de Sacerdotes, de la Colegial del Salvador, participó de estos ideales contrarreformistas y los plasmó en las pinturas de su capilla dedicadas a su titular, siguiendo en su iconografía "militante", temas de plena ortodoxia católica. A pesar de ello, teólogos de la Contrarreforma no tuvieron el menor recelo en aceptar temas, apócrifos, como el Domine, quo vadis, acatando la autoridad moral de insignes personajes de la Iglesia como el cardenal César Baromio o Juan Molano.

(13) Male, E., L'Art. religieux aprés le Concile de Trente, París, 1932, págs. 45-48.

(14) López de Ayala, I., El Sacrosanto y. Ecuménico Concilio de Trento. Traducido al idioma castellano por..., Madrid, 1798, págs. 349-393. 


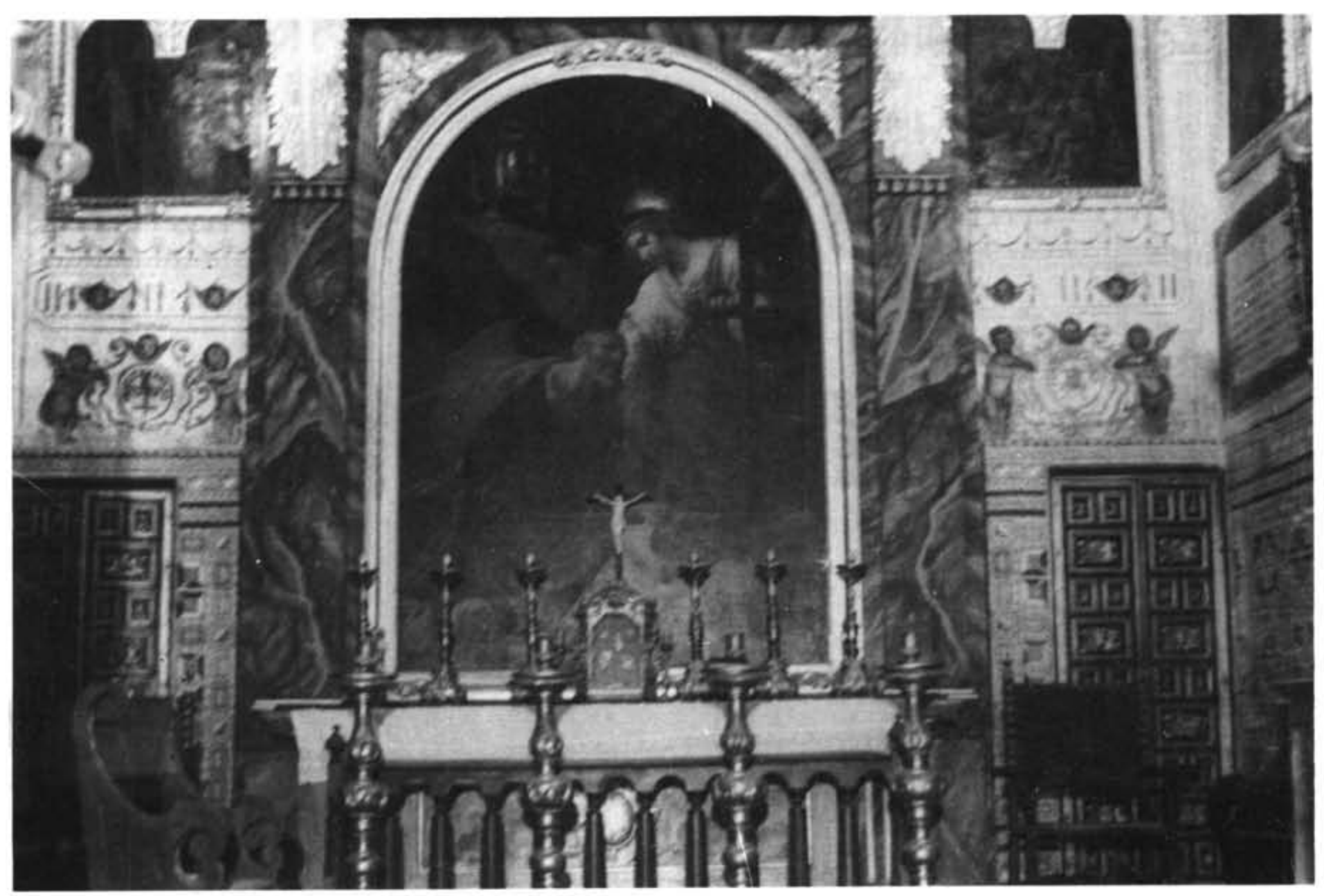

f

5
$\frac{5}{5}$
5
5
5
5
$\frac{1}{1}$
$\frac{1}{2}$

Fig. 1 Interior de la Capilla de la Hermandad de San Pedro ad Víncula 


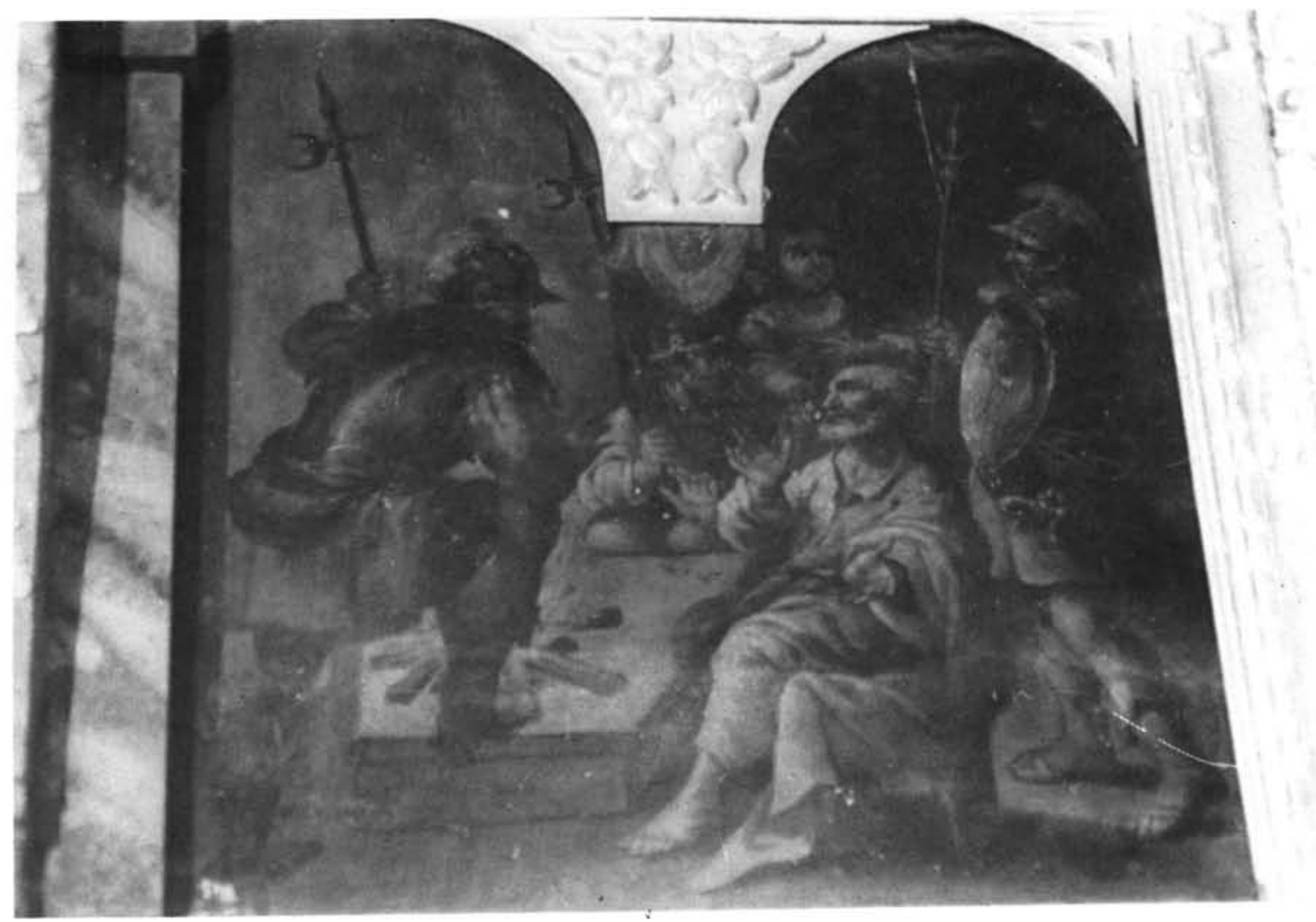

Fig. 2. Taller de Matías de Arteaga. Negaciones de San Pedro 


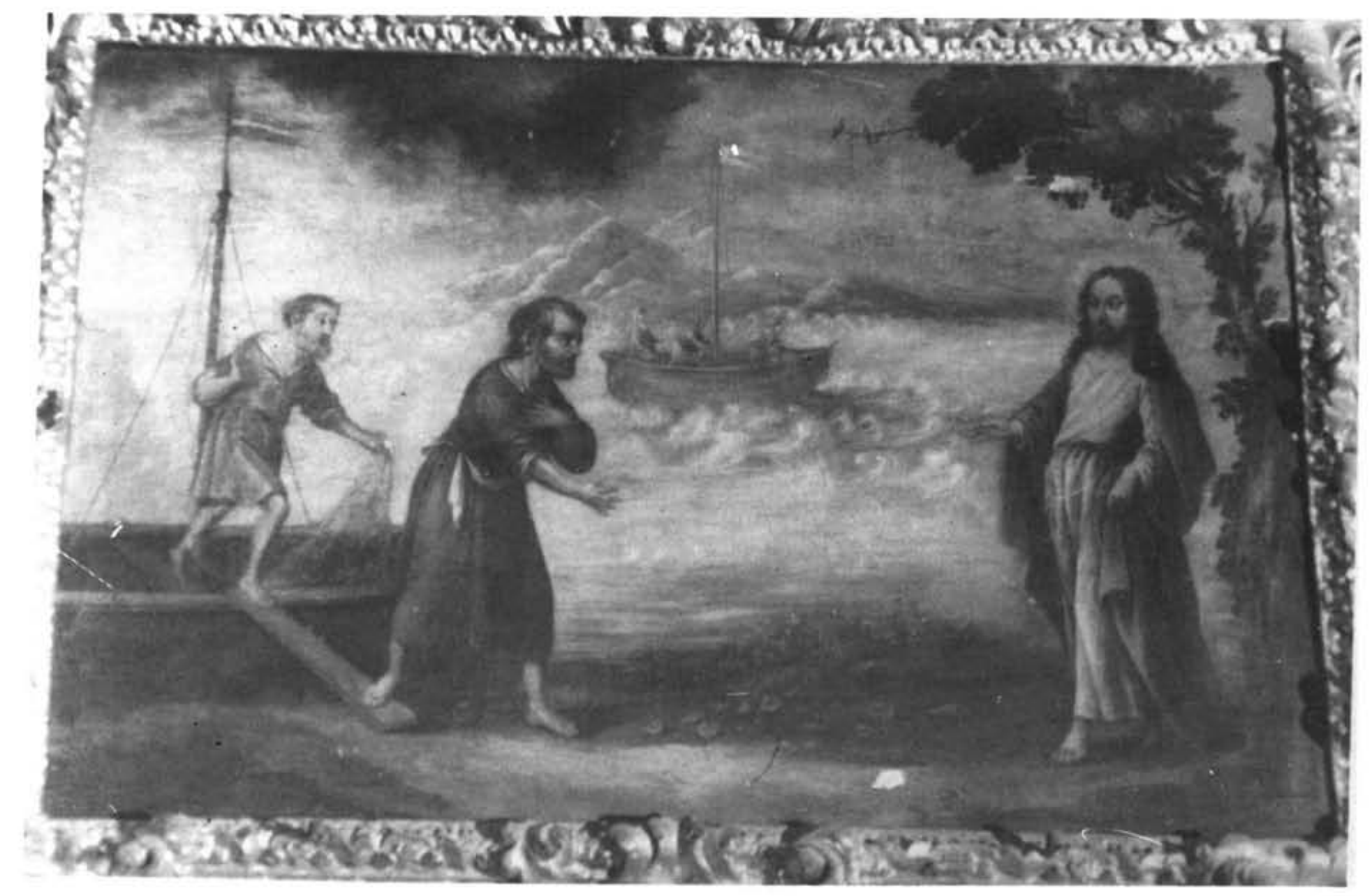

Fig. 3. Taller de Matías de Arteaga. Vocación de San Pedro y San Andrés 


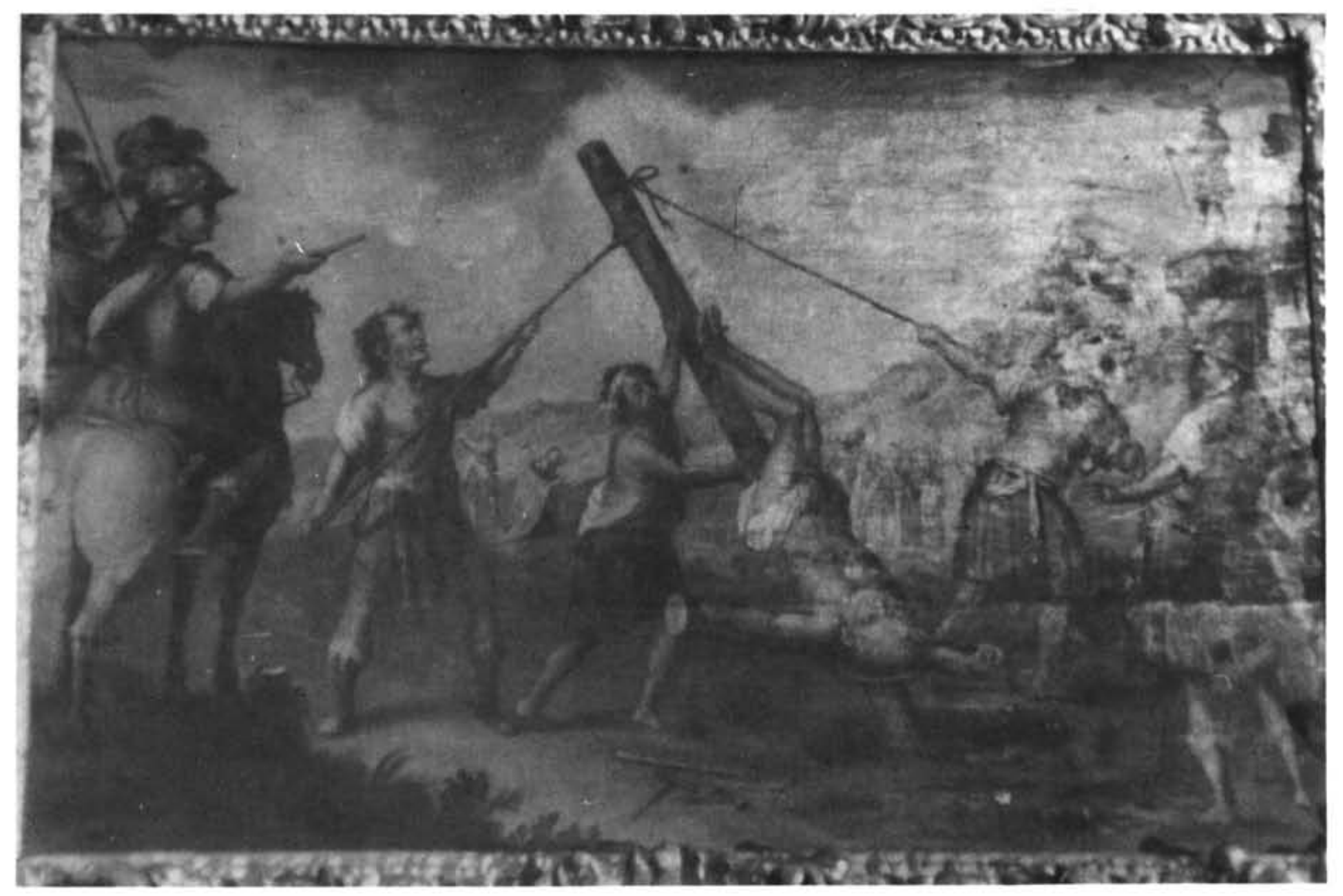

Fig. 4. Taller de Matías de Arteaga. Martirio de San Pedro 


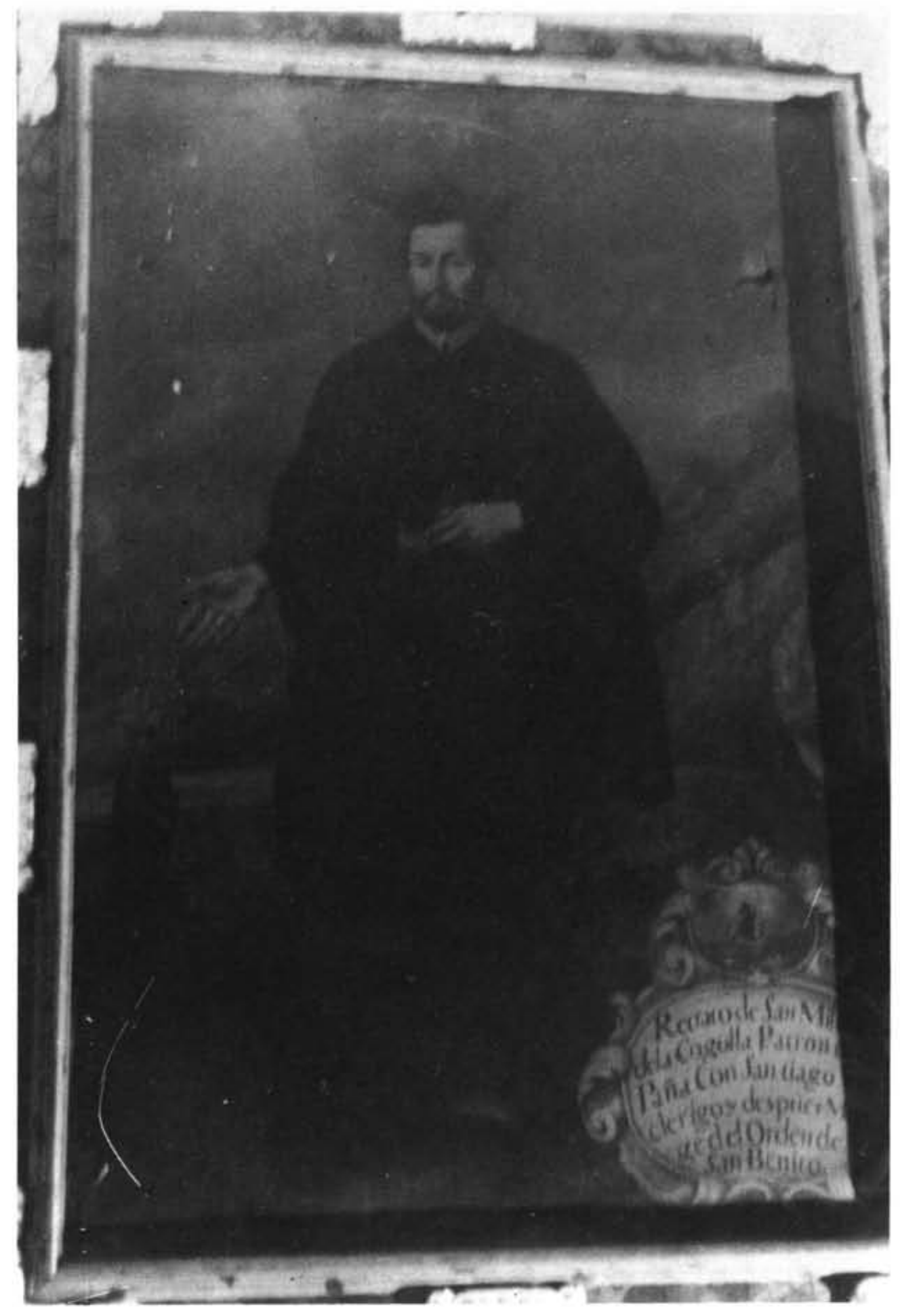

Fig. 5. Anónimo. San Millán de la Cogolla 